\title{
EDUCAÇÃO PROFISSIONAL E TRABALHO: AINDA É POSSÍVEL?
}

\section{Professional education and work: is it still possible?}

\section{Educación profesional y trabajo: ¿todavía es posible?}

\begin{abstract}
RESUMO Começando com a concepção de transformações do mundo do trabalho e seus desafios em correlação com a EPT, o presente ensaio trata, inicialmente, questões acerca de narrativas teóricas e o papel da crítica. Em seguida, mira a respeito de aspectos importantes das tecnologias, técnicas e o lugar do trabalho na história: a não humanidade do trabalho, mas sim sua inscrição histórica e social. Isso permite definir um campo teórico e cultural no qual se insere o sofrimento humano. Após delimitar e construir essa base de questões necessárias sobre crítica, narrativas, o trabalho como componente histórico, técnicas e tecnologias pode-se, então, abordar o mundo do trabalho e suas transformações históricas com destaque para a contemporaneidade. Por fim, em chave de conclusão, discute-se o papel da educação profissional e seus aspectos educacionais, ideológicos e simbólicos a nortear a vida e a psique humanas.
\end{abstract}

PalaVRas-ChaVe: Trabalho. TeCnOlOGias. Técnicas. CRíticA. IDEOLOGIA.

ABSTRACT Beginning with the conception of transformations of
the world of work and its challenges in correlation with EPT, this
essay intends initially to address questions about theoretical nar-
ratives and the role of criticism. It then looks at important aspects
of the technologies, techniques and place of work in history: the
non-humanity of work, but its historical and social inscription.
This allows defining a theoretical and cultural field in which hu-
man suffering is inserted. After delimiting and building this basis
of necessary questions about criticism, narratives, work as a his-
torical component, techniques and technologies, one can then
approach the world of work and its historical transformations,
highlighting contemporaneity. Finally, in conclusion, the role of
professional education and its educational, ideological and sym-
bolic aspects to guide human life and psyche. KEYWORDS: WORK. TECHNOLOGIES. TECHNIQUES. CRITICISM. IDEOLOGY.

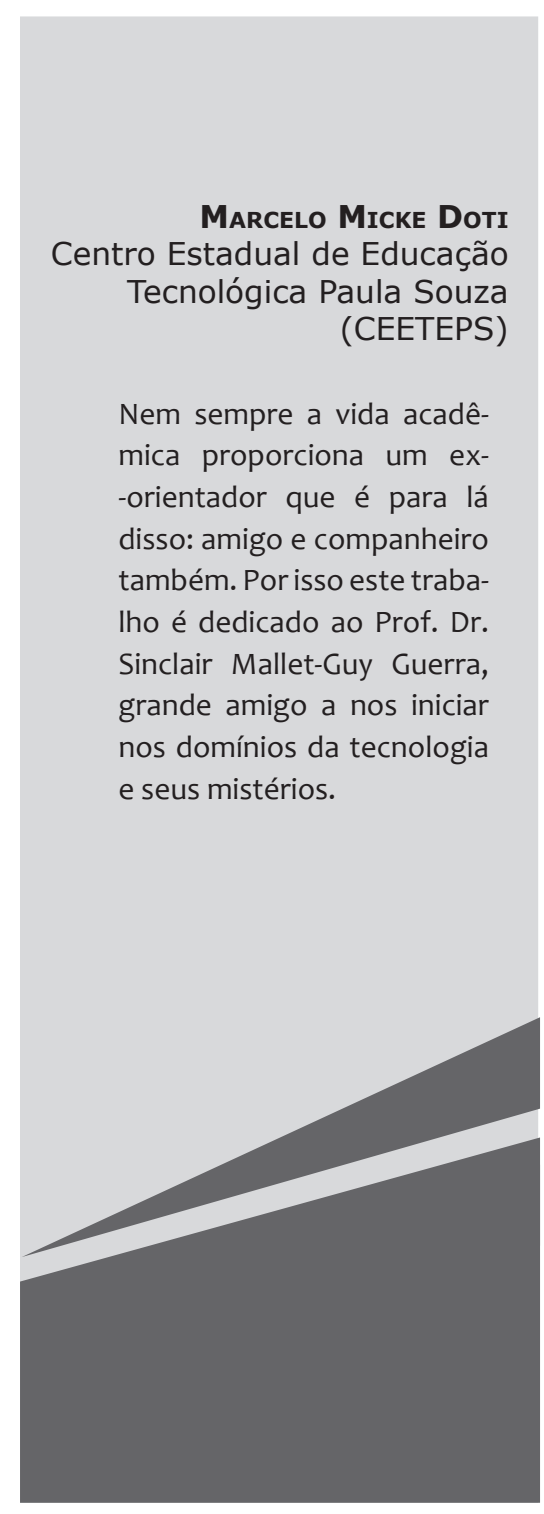


RESUMEN Empezando con la concepción de transformaciones del mundo del trabajo y sus desafíos en correlación con la EPT, el presente ensayo pretende, inicialmente, abordar cuestiones sobre narrativas teóricas y el papel de la crítica. En seguida se centra en aspectos importantes de las tecnologías, técnicas y el lugar del trabajo en la historia: la no humanidad del trabajo, sino su inscripción histórica y social. Esto permite definir un campo teórico y cultural en el que se inserta el sufrimiento humano. Después de delimitar y construir esa base de cuestiones necesarias sobre crítica, narrativas, el trabajo como componente histórico, técnicas y tecnologías se puede entonces abordar el mundo del trabajo y sus transformaciones históricas con destaque para la contemporaneidad. Por último, en clave de conclusión, el papel de la educación profesional y sus aspectos educativos, ideológicos y simbólicos a orientar la vida y la psique humanas.

Palabras clave: Trabajo. Tecnologías. Técnicas. Crítica. IDeOLOGÍA.

\section{Mundo E TRABALHO: NARRATIVAS TEÓRICAS E CRÍTICA COMO PRESSUPOSTOS}

A problemática do trabalho é histórica. Dizer isso é basicamente entreter-se com a obviedade. No entanto, ao dizer histórica é preciso questionar-se qual historicidade. Qualquer processo de constituição, de construção de determinado tipo de interação humana ou sociabilidade, pode ser visto ou narrado sob determinados pressupostos. Com o trabalho não é diferente e perguntas podem e devem ser feitas neste sentido: qual trabalho? Em quais condições sociais as pessoas interagem por meio do trabalho? O trabalho humano se dá sob quais condições de necessidades e possibilidades? Qual o status político no qual se dá esse trabalho: em condições de liberdade e qual liberdade? Poderíamos continuar colocando mais e mais questões, indagações e certamente todas como provocações, não simplesmente um amontoado mecânico de frases a serem respondidas. Em cada pergunta um delineamento da narrativa sobre o trabalho e as formas assumidas pela educação para o trabalho. Percebe-se assim a possibilidade de entender e precisar o sentido lapidado, mais articulado da afirmação inicial deste ensaio.

Praticamente desnecessário dizer: o trabalho é atividade humana básica. No entan- to, ao colocar dessa forma usamos o discurso construindo outra narrativa explícita e potencialmente ainda outra implícita. Verifica-se desde já um processo teórico em primeiro lugar no nível do discurso bastante complexo: expor um processo histórico não é um fato social simplesmente como gostaria o viés positivista da sociologia, da economia e outros tantos campos de percepção, compreensão e entendimentos dos objetos sociais. Ao observar um objeto social já o construímos sob determinada episteme, determinada hermenêutica. Isso pareceria levar a uma espécie de "atoleiro teórico" sem fim e relativista. Ao contrário: revela e eleva o conhecimento dos processos sociais em sua complexidade, multiplicidade de articulações, interfaces. Resulta disso uma capacidade de interpenetração maior das capacidades da linguagem como promotora das construções teóricas para nós. Em outros termos, a capacidade de articular objetos sociais construídos pelo discurso diante dos processos históricos. Seria mais ou menos a tese básica de todo materialismo: há um ser cujo pensar nunca abarca completamente, mas não nos impede de construí-lo mediante capacidades de entender as manifestações históricas e o diálogo das "falas" teóricas. Longe de ser ecletismo teórico, tenciona-se com esses desenvolvimentos transformar múltiplos diálogos em "falas", encontro social pelo discurso, pela 
teoria, trazendo autores diferentes dentro de uma demanda crítica.

Antes de prosseguirmos, é recomendável colocar o significado de crítica, ou demanda crítica como já aludido. Já argumentamos em outra oportunidade (DOTI, 2018a) que tomar uma palavra pela sua etimologia pode ser um "pecado teórico". A etimologia pode tão simplesmente ser uma ruína, um pedaço destruído de um templo que, mesmo belo, não possui mais a instância simbólica da sociedade sobre a qual apoiava seu significado e multiplicava seu significante. Palavras tomadas etimologicamente podem ser indicativos, mas podem incorrer em erro grotesco: ao apelar para a etimologia ganha-se o passado, ergue-se a erudição, põe-se a conhecer, mas se perde o presente, perde-se seu significado, seu simbolismo na ordem do discurso atual: ao ouvi-la, nossa imagética e capacidade de articulação irá remeter para o seu senso atual. Porém, esse senso atual pode ser o senso comum: pior inimigo das construções intelectuais, pois totalmente recheado de instâncias ideológicas e de poder simbólico proporcionando as mais duras e estúpidas formas de pragmatismo. Parece novamente um relativismo com muita lama teórica.

Nossa proposta é entremear discursos e narrativas como fonte de determinada fala, não a língua adâmica, universal, mas a fala da enunciação. O lugar de fala será sempre barrado, barrado pela sua limitação de ser determinado discurso em determinada narrativa. Nesse sentido, procedemos a determinada concepção de crítica, uma narrativa específica sobre a demanda crítica como evitação do relativismo e posicionamento social.

A demanda crítica no encontro de falas discursivas possui para nós alguns elementos marcantes e precisos. Trata-se de determinada concepção teórica, de uma construção a qual não se satisfaz com o fácil, com a "repetição do mesmo", é uma construção em si mesma "nômade" (SCHÖPKE, 2012). Sua dúvida nômade e contínua não a deixa aterrissar no fácil, na filosofia do fundamento, no sistema: precisa continuamente brotar e morrer. Em termos culturais e históricos (como se um se desvencilhasse do outro), é uma concepção própria aos séculos XX e XXI: não há lugar estável, nem para o trabalhador, nem para o intelectual. Como veremos, no entanto, são posturas distintas: o que para um é "corrosão do caráter”, desarticulação da vida, insegurança e desamparo, para o outro pode (ou deveria) ser parte de um programa integral de construção teórica e de vida. Sendo a crítica essa concepção teórica não contente com a filosofia do fundamento e nômade por essência e vocação afetiva, ela é abrangência e multiplicação de diálogos e falas. Ao dizermos anteriormente trazer discursos de campos variados para uma demanda crítica era a isto que nos referíamos: não um ecletismo, porém um nomadismo não satisfeito com a estagnação.

No entanto, nossa concepção de teoria e crítica sintetizada como concepção teórica não subjaz apenas no nomadismo. Ainda há um ponto cego, uma sombra, algo escondido como o recalcado querendo aflorar e pôr à luz um ecletismo satisfeito apenas com suas palavras, com sua ordenação discursiva. Satisfação intelectual essencial para o pensar - o prazer do pensar - que irá esconder de qualquer forma uma sempre possível objeção: não há nisso uma ética, não há postura política. O "Grande Hotel Abismo" estaria posto aqui e não na Teoria Crítica: um pensar que flana e deve flanar, porém pode tomar posição. Há muito disso nos assim chamados "teóricos da pós-modernidade": acertos precisos especialmente sobre as problemáticas da totalidade e das metanarrativas. Entretanto, parece que muitos de seus leitores se imobilizam e se satisfazem com certo imobilismo teórico e político, desconstrução ideológica e apologia ideológica do fim das ideologias. Daí muitos seguirem por caminhos até mesmo conservadores. Não é o caso da nossa postura de crítica e nesse ponto um pouco de etimologia pode ser bom.

A palavra crítica está ligada à palavra grega krimein, quebrar. Nesse sentido, ser crítico é quebrar tanto uma obra de arte, como conceitos, como formações ideológicas e 
simbólicas do senso comum. Destruir e pôr em pedaços para, então, analisar, juntar e tirar daí novas concepções, novos "olhares", novos discursos e potenciação de novidades. Pela via dessa etimologia a palavra liga-se, facilmente perceptível, com a palavra crise, momento de decisão: quebrar é colocar o posto, o aparente, o óbvio talvez, em crise e dele retirar espessuras discursivas diversas. Ao quebrar conceitos e ideias, colocando-as em crise, obtém-se a possibilidade da interação discursiva: algo que cada vez menos se faz na sociedade das comunicações sem a presença. Neste ponto, adiantamos algo que ainda virá: a educação profissional desaparece exatamente no momento em que desaparece o outro da presença, da fala e da crítica. Só há processo de desenvolvimento intelectual e profissional quando a presença é permitida, a crítica age diluindo, destruindo, pondo abaixo o mundo, quebrando, mas possibilitando a presença do outro e do discurso do outro. $\mathrm{O}$ ser humano não se faz pelo trabalho, faz-se pela presença e pela simbolização. Discorreremos mais a respeito disso depois.

O apoio etimológico resgatado aqui serviu para colocar os elementos de um nomadismo como crítica e trazer outros discursos possíveis por meio da crítica, do "quebrar”. Trazer outros discursos mantém relação com o que falávamos sobre a interação destes e de narrativas pela "quebra", trazendo outros diálogos e interpenetrações teóricas importantes. Há, no entanto, um momento em que isso se diferencia do ecletismo já referido: ao "quebrar", desconstruir o fazemos sobre o existente - um discurso, uma ideologia, o senso comum, poder simbólico etc. Ao fazer isso acerca de determinada realidade configurada como narrativa socialmente aceita, o fazemos deixando uma abertura para uma aposta: dentro de todos os pedaços postos abaixo, quebrando e quebrando, acabamos por chegar no ponto no qual o elemento político adentra nossos discursos. Diante disso temos nossa aposta política, conceitual, individual, estilo de vida e, especialmente na contemporaneidade em que a ideologia e a cultura se entrelaçam formando quase um automatismo simbólico (DOTI, 2018a), uma aposta crítica de toda realidade. Assim, atravessando etimologia e resgatando o que nos interessa de seu túmulo - o túmulo etimológico - pode-se chegar ao outro e se articular com a aposta para dizer que ser crítico é ver pelo outro: o outro, a alteridade da sociedade, da realidade e da cultura atuais.

Ao se chegar aqui, já não é possível retorno e se percebe que ser crítico é ser radical em todos os sentidos da palavra radical e o mais interessante para nós: pela raiz, criticar e subverter tanto o pensar, como subverter a realidade e sua cultura. Proporciona-nos esse caminho outro momento essencial: a crítica é o momento da identidade intelectual, o momento no qual, uma vez percorridos caminhos e trilhado veredas, desertos e caminhos cerrados, encontramos algo em nós que nos faz um eu intelectual diante de outros. Não os exclui, mas coloca esses outros diante de nós e não nos furtamos a estar com, mas também sermos um. O senso comum, por exemplo, não permite ser um. Pior: na atualidade das TICs o senso comum é ser com todos, ser massa, perder-se na noite fria e inorgânica do nada da pulsão de morte. ${ }^{1}$

\footnotetext{
Em Freud, o conceito de pulsão de morte é desenvolvido mais tardiamente e provocou celeumas. A pulsão de morte é quando o trabalho do eu é paralisado em direção a desejar não mais desejar. Há uma estagnação desse trabalho e o eu se converte em processo de repetição, apatia, ou, em tom de galhofa, em "zumbilânida". É a provocação da dor e da paralisia. E essa dor e paralisia podem ter significados agônico, pensando agonia tanto como dor, como em seu significado alemão, Angst, medo. Mas acontece algo estranho nos tempos do capital do século XX: o supereu (Überich) exige prazer e desejo, múltiplos desejos, pois são necessárias todas as formas de gozar a vida. A pulsão de morte é aqui um pulsar em um looping de alegria que é angústia também, pois são as exigências do gozar social, do exibicionismo, de se mostrar em felicidade com a vida, quando não mais é vida, é morte. É o gozo do outro. Sintomático disso são os discursos dentro do sucesso, da qualificação profissional para se obter emprego e sucesso, dinheiro. Tudo isso abre um espaço gigante para agonizar alegre e ser reprovável o discurso da melancolia e da morte. Estar solitário é estar na infelicidade. A bibliografia é vasta e indicaremos alguns: FREUD (2010 e 2014), GIACOIA (2008), GARCIA-ROZA (1986).
} 
Fechamos, assim, um ciclo que foi da necessidade teórica do objeto construído para e pelos discursos, a necessidade desses e um aparente ecletismo, em si não ruim, mas podendo produzir tão-somente estagnação teórica, ideológica e política, até a aposta e a identidade intelectual que a crítica proporciona, posicionando-nos no mundo e assumindo nossos lugares de enunciação.

\section{Mundo do trabalho OU MUNDO das TÉCNICAS: O SOFRIMENTO HUMANO}

Teremos que voltar à afirmação já feita a qual, depois, tivemos que adentrar para as questões teóricas sobre narrativas em torno da própria forma de apreensão da realidade, o significado mesmo de realidade como narrativa social aceita ou erigida ideológica e simbolicamente pelo poder, pelo estatuto da interpelação ideológica e tantas outras formas mais de dizer o que é realidade e o que não é. A afirmativa dizia respeito ao trabalho como atividade básica do ser humano. E ainda fazíamos observações a respeito de narrativas implícitas ou explícitas. Delinear o significado disso e o motivo do excurso teórico do item anterior é essencial.

Atividade básica no sentido de termos nos gestos, nas palavras, no poder da linguagem e da simbolização, assim como nos atos, na manipulação de instrumentos, de objetos, de materiais, fatos, ou antes, existentes de nossa vivência. O trabalho é, neste caso, por esta narrativa, uma perspectiva dos atos humanos, do seu fazer técnico. E o fazer técnico é parte constitutiva da comunicação humana, parte do seu colocar-se no mundo tal como os gestos e as palavras. Trata-se de determinada forma de fazer e manipular instrumentos e qualquer objeto, material, simbólico, ideias. A técnica é, por esta narrativa (DOTI, 2018e), determinado ato posto no mundo como trabalho.

Há mais nisto: sendo a técnica uma linguagem entre outras, mas linguagem que conjuga em si atos e falas, gestos e símbolos, instrumentos, ferramentas e desenhos, a técnica acaba por se colocar como a forma pró- pria do existir humano como ser que se movimenta. Possuindo a sua propriedade em uma linguagem, a técnica é uma estrutura paranoide. Em outros termos, o "eu" do ato técnico é semelhante à constituição do eu paranoide de Lacan: o eu só se faz através do outro. Ao ser um eu instaurado em uma subjetividade esta só se faz na linguagem. Ao estarmos na linguagem já estamos no domínio da subjetividade, ou seja, um eu que não é indiviso, não é indivíduo, o não divisível, mas o totalmente divisível já que constituído no outro. A técnica está no ser humano, pois ele se locomove e gesticula, mas como a linguagem falada, sendo a técnica uma linguagem ela nos coloca como estrutura paranoide também: meus atos técnicos são os atos sociais, meus atos técnicos como linguagem do meu corpo em movimento são um movimento no outro. É o povoamento literal do meu ato pelos outros, do meu ato pelas outras linguagens técnicas em uma estruturação simbólica. Esta é a narrativa explícita a qual fizemos referência.

Antes de elucidar a outra narrativa teórica, implícita advinda de determinada tradição marxista, convém algumas questões importantes sobre a relação entre técnica e tecnologia o que levará às problemáticas atuais do trabalho. Na medida em que as formações históricas, sociais e culturais vão se construindo e dentro delas fraturas sociais ocorrem, também temos divisões sociais marcadas de diversas maneiras em função de todo um conjunto político, religioso, simbólico, econômico, constituindo castas, classes, estamentos entre tantas formas de distinguir e deslocar os seres humanos em agrupamentos sociais. Antes mesmo dessas fraturas sociais, temos o aparecimento das técnicas reguladas em tecnologias: assim a quase "potencial possibilidade" de fazer o que quiser e viver livremente suas técnicas como só os "loucos" fazem, as técnicas são linguagens sociais que não nos deixam "escapar" do outro social; menos ainda quando tecnologias, "coágulos" materiais e abstratos dos atos técnicos em processos sociais nos são postos. É uma primeira forma de sujeição. Não poderíamos dizer que 
uma das primeiras sujeições humanas, além daquela da fala, é a sujeição do movimento? Mais que isso virá depois: as fraturas sociais mencionadas transformam as tecnologias em processos de regulamentação das técnicas, do corpo, do tempo, dos gestos e dos espaços da realização subjetiva. Com as várias formas de estratificação social ao longo da história, as tecnologias mais desenvolvidas e com maior capacidade de produção de riqueza socialmente aceita e em circulação estão e são controladas pelo estrato social do poder. Se a tecnologia é em si uma "trava" da técnica, quando convertida em tecnologia para uma fração da sociedade produzir e concentrar, açambarcar riqueza, mais ainda a técnica se transforma em algo sujeitado. O ser "louco" e viver livremente se transforma em uma impossibilidade cada vez mais distante e apenas visível no reino do fantástico. Nas amarras do capital e da sociedade capitalista, a sociedade mais tecnológica a pisar sobre o planeta, isso é a crueldade total sobre a liberdade. ${ }^{2}$

Por esse viés, é necessário verificar que o conceito de trabalho é histórico: o trabalho não é base humana. Não é atividade essencial. Sim, há contradição com o que dissemos e o desenvolvimento teórico visto até aqui permite essa virada conceitual. A atividade essencial é a técnica e as linguagens humanas que a ela se adicionam para que o ser humano seja o ser humano. O ser humano se transforma de Homo sapiens em humano por meio de todas as linguagens que o constroem, processo no qual as técnicas são uma das formas, não o trabalho. O trabalho é tortura sim, não base da sociabilidade. É tortura e não só em sua origem etimológica mais do que conhecida (tripallium, três paus): é tortura por ser o oposto

\footnotetext{
Verificar que não desenvolvemos o conceito de tecnologia em sua acepção etimológica de estudo das técnicas ou coisa do tipo. Procuramos outra confecção e feitura entretecida das ideias. Para o conceito de tecnologia em várias línguas, ver Ruy Gama (1986). Ver também o conceito de tecnologia em Álvaro Vieira Pinto (2005). Liberdade também não foi desenvolvida aqui e nem cabe neste texto. $O$ que se pode aferir do indicado no texto é a liberdade como potencialidade da realização das técnicas dentro de uma sociedade sem sofrimento, sem sintoma (DUNKER, 2015).
}

da liberdade das técnicas e as linguagens da liberdade, o desenvolvimento humano sem sofrimento. O trabalho não é base trans-histórica alguma do ser humano, do "ser social e sua ontologia”. O trabalho é forma histórica em seu próprio desenvolvimento em relação às técnicas humanas.

Aparece agora facilmente a outra narrativa em torno do trabalho como categoria essencial e base da sociabilidade humana. Trata-se da argumentada narrativa implícita: é determinada leitura de Marx que passou a vigorar em muitos meios acadêmicos especialmente ligado à tentativa de Lukács em erigir uma "ontologia marxiana". Postone (2014) já adverte para os problemas dentro desse marxismo tradicional em colocar uma narrativa histórica transcendente do trabaIho. Esse tipo de narrativa possui problemas não apenas teóricos como os arrolados por nós ao fazer colidir os conceitos de técnicas, tecnologias, fraturas sociais nas diversas formações socioculturais e o trabalho, como também problema de ordem da política e da necessidade revolucionária: a superação do capital e sua sociedade capitalista não se dá apenas pela eliminação do mercado e a posse coletiva dos meios de produção. É preciso repensar as questões da cultura, mas também das tecnologias produtivas, entre outras, para uma emancipação que seja o mínimo de sofrimento possível.

\section{AS TRANSFORMAÇÕES DO MUNDO DO TRABALHO}

A sociedade do capital e seu "movimento de valor" na busca de mais valor e acumulação de riquezas é, sem dúvida, a sociedade mais tecnológica jamais existente. A sociedade que mais colocou a tecnologia como ponto chave de todos os seus processos de mediação social: desde o aceleramento da produção, a automação da produção, a organização do trabalho, o disciplinamento na fábrica, a grande indústria, o disciplinamento dos gestos e atos, o gerenciamento da percepção, a produção em massa de informações, o domí- 
nio da informação como produção em massa da mesma, até chegar em formas nada sutis de "falsa consciência" em massa com meios tecnológicos de telecomunicações (TICs) e a captura que estas podem promover dos afetos. Trata-se de uma interpelação do Es freudiano (DOTI, 2018d).

Podemos escrever com outras palavras o início de O Capital para sustentar a nossa argumentação em relação ao item anterior. O primeiro parágrafo d'O Capital diz que nos lugares em que domina o modo de produção capitalista a riqueza aparece como uma enorme coleção de mercadorias. ${ }^{3}$ Assim, na sociedade dominada pelo modo de produção capitalista a riqueza que aparece como mercadoria é produzida com sofrimento. Sofrimento no produzir e sofrimento no consumir. Sofrimento do sem sentido da produção, sofrimento da exaustão, sofrimento de salários reduzidos e desamparados sociais afinal, no quadro do neoliberalismo o Estado não é ausente, mas "correia de transmissão" para a acumulação privada de capital como nos mostra, por exemplo, o quadro absurdo da dívida pública em muitos lugares do mundo; trata-se, portanto, de um novo Estado, o Estado do desamparo social, não mais welfare state. ${ }^{4}$ Portanto, na vivência da produção econômica, o sofrimento é uma das formas do disciplinamento das técnicas pelas tecnologias de outro: é o outro do capital como desejo, mas desejo imperioso e do qual, furtar-se do mesmo, é se furtar de viver, pois não mais se terá meios materiais e espirituais para a vida. Um quadro tão grande de sofri-

3 "A riqueza das sociedades em que domina o modo de produção capitalista aparece como uma 'imensa coleção de mercadorias', e a mercadoria individual como sua forma elementar. Nossa investigação começa, portanto, com a análise da mercadoria" (MARX, 1985, p. 45).

4 Nunca esquecendo que nos países periféricos da ordem do capital no contexto do pós-Segunda Guerra Mundial, o Estado de bem-estar social, o welfare state, jamais existiu. Algumas conjunturas como o chamado período populista de nossa história e de outros países permitiram alguns ganhos trabalhistas em quadros marcados por fortes alianças com elites locais e suas classes de sustentação como setores exportadores, latifundiários e empresariado desnacionalista. mento parece fazer da morte o mais doce dos remédios.

O mundo do trabalho e suas transformações são um recorte, uma narrativa posta em função da proposta deste ensaio. A sociedade do capital adquiriu tanta complexidade e diversidade de aspectos a nos tolher a liberdade, nos colocar de joelhos como sujeitados e dominados, que decidir qual narrativa da sujeição, dominação e, em muitas vezes, qual humilhação escolher para narrar a história dos marginais e excluídos é difícil. A narrativa ou recorte do mundo do trabalho é uma delas, uma das histórias possíveis dessa marginalização, dessa sujeição e dominação. O trabalho - em vista do discutido no item anterior e a historicidade de seu conceito - não nos dignifica e os ditos sobre o enaltecimento do homem no trabalho são das mais bárbaras violências: estupidificadora e ilusionismo. Projeta-se, então, um delineamento já percebido nos itens anteriores: a sujeição e dominação das potencialidades de liberdade do ser humano; potencialidade a lhe dar um mundo no qual o ser não está à espera, o ser não é, mas o ser se faz e, uma das formas de o fazê-lo, é pelas técnicas. Por intermédio desta narrativa da sujeição, o mundo do trabalho surge como uma das potencialidades da sujeição. Mais: a educação profissional e o mundo do trabalho como afunilamento da narrativa. E por isso a pergunta título deste ensaio: é possível educação profissional e trabalho? Claro que é, para alguns. No entanto, se a resposta levar em conta a articulação já posta de técnicas e tecnologias e a historicidade do trabalho e ainda mais sua perspectiva no capitalismo a resposta é negativa em sua relação com a liberdade. Veremos isso adiante, mas deveremos adicionar elementos não só teóricos como também históricos para fazer convergir a problemática da educação profissional e trabalho.

Antes de prosseguirmos, é interessante uma "pequena nota". Pequena apenas em seu tamanho, nunca em seu peso histórico; aquilo que é uma espécie de "paradigma do mundo moderno do trabalho". Quando falamos de educação profissional, trabalho, 
transformações do mundo do trabalho, os novos disciplinamentos e gerenciamentos, o mundo de molde ocidental forjado pela indústria e educação ocidentais esquecemos a "carne mais barata do mercado", ou seja, esquecemos o primeiro trabalho altamente disciplinado, gerenciado, sujeitado, dominado, amaldiçoado e segregado nos inícios do capitalismo: o trabalho negro e escravizado. Esta foi a primeira forma de trabalho marcada pelo alto poder de trabalhar sob disciplina da produção, verdadeiro empreendimento contábil e racionalizado. Porém, não era dentro da grande indústria e esquecemos disso muitas vezes. Não há pecado em esquecer: fomos instruídos para isso. ${ }^{5} \mathrm{O}$ pecado é não lembrar e jogar o passado fora: não se joga o "anjo da história" fora impunemente.

O capitalismo como a afirmação da produção de valor e a colocação do valor em movimento se dará em definitivo no século XIX especialmente com a grande indústria moderna. Neste momento, após meados do século XIX, a classe operária já está plenamente formada e já destroçava seus dedos e braços nas camas quentes que nunca esfriavam, como Marx nos descreve no primeiro volume de $O$ Capital. Também a luta entre capital e trabalho - ou talvez devêssemos dizer, entre capital e sua dominação e técnicas humanas, técnicas do ser livre - já ocorria de todas as maneiras e formas possíveis. Nesse momento histó-

\footnotetext{
Assinalamos anteriormente o esquecemos não sem propósito: nossos livros não enfocam isso, nossas pesquisas quase nunca enfocam isso, nossa razão de entendimento do capital esquece isso. Marx o lembra no capítulo XXIV de O Capital, "A assim chamada acumulação primitiva". Quase sempre narramos pelo viés do século XIX e a grande indústria o disciplinamento fabril. Assim, mesmo revolucionários, mesmo radicais na ruptura social, esquecemos o que era para esquecer, o que deveria ficar em nossa Verdrängung, em nosso recalque inconsciente: o trabalho negro escravizado. Até o escravizado esquece isso. Mais: fomos construídos intelectualmente para foracluírmos como fazem os psicóticos essa forma de trabalho. O esquecer é construção histórica como o lembrar e, neste caso, uma construção para o esquecimento tão forte na qual até nós, críticos, esquecemos a tradição dos excluídos que deveria sempre nos lembrar ser o estado de exceção regra não a exceção.
}

rico, a maquinaria surgia como a forma final de subsunção do trabalhador ao capital, mas também transformação no mundo do trabaIho e das técnicas cada vez mais para longe da liberdade. Diante desse quadro, percebe-se que a liberdade não pode ser apenas um sonho, lindo e fantástico, poderoso nos afetos como em "Um Sonho de Liberdade" (The Shawshank Redemption, 1994). Evidente que o poderoso afeto estimulado em "Um Sonho de Liberdade" se dá pela linguagem do mesmo: trata-se de cinema e assim é parte de sua linguagem o estímulo dos afetos. Mas Andy Dufresne (Tim Robbins) não sonhava apenas: sua vontade de liberdade era "geológica", programada e calculada como os movimentos geológicos lentos, mas inevitáveis, constantes, eternos do planeta. A liberdade deve ser um programa e os trabalhadores logo perceberam isto: a necessidade de programas e de partidos e a construção de um conceito de liberdade, a liberdade como o oposto do capital e seu controle, sua sujeição e seus desejos dominadores.

Ao longo do século $X X$, temos transformações mais significativas ainda. Se nos países centrais o pacto fordista, como diz Harvey (2013), ${ }^{6}$ garantia a estabilidade de emprego e o fordismo era muito mais do que uma organização do trabalho, mas uma concepção de sociedade e acordo capital/trabalho garantindo o estado de bem-estar social, nos países periféricos os problemas eram outros: em alguns ainda era a luta pela descolonização a dura realidade, em outros a afirmação de necessidades de exportação de seus poucos produtos primários. Em alguns, no entanto, como já salientamos em nota, como o Brasil, tentávamos construir os pactos populistas de disciplinamento do trabalhador mediante alguns direitos. Direitos esses em declínio crescente aqui e alhures. No entanto, o mundo feliz da história de amor que bem ou mal ia se construindo em vários

6 A melhor ilustração em película de cinema mostrando claramente as diferenças entre a insanidade financeira atual e o trabalhador que tinha garantida sua "história de amor com o capitalismo", pois estaria seguro para viver bem é justamente o documentário de Michael Moore, Capitalismo, a love story (2009). 
lugares do mundo tinha seus dias marcados para morrer. Esse pacto fordista não chegaria a viver muito. As próprias regulamentações de Bretton Woods estariam fadadas a desabar, especialmente um dos maiores golpes financeiros da história mundial: a desregulamentação do dólar, sua inconvertibilidade em ouro e os dias anunciados ao capital volátil, financeiro e flexível dos grandes mercados. E esse capital volátil e altamente flexível não era apenas rápido em relação à sua forma financeira que avançava mais dentro da contabilidade empresarial das corporações; ele passava a ser também uma exigência de curtíssimo prazo, lucros enormes e rápidos. Não à toa as considerações postas por Harvey (2013) e a compressão espaço-tempo como característica do fenômeno pós-moderno, mas também a nossa sensação pessoal de um mundo instável, fugidio, difícil, incompreensível como consequência da referida compressão. Nosso corpo de afetos e o desamparo, insegurança como característica marcante de nossas vidas é a marca de nossa depressão. ${ }^{7}$

No mundo do trabalho, o impacto dessas transformações se anunciava gigante. Ao longo dos anos 1960, a rentabilidade das grandes corporações e do sistema como um todo entra em declínio. Na década de 1970, mais problemas aparecem: os choques do petróleo só abalam a vida de quem vive de salários; nunca de uma commodity com preços cotados em mercados de futuros e a possibilidade existente em toda commodity, ou seja, ser um ativo financeiro e especulável. O deslocamento produtivo de empresas instalando suas filiais em outros lugares do mundo não era um fato novo e não o é. Porém, perda de lucratividade, especulação contra o dólar obrigando

\footnotetext{
7 Em recente apresentação na ANPOF (23 de outubro de 2018), colocamos essa interface do ideológico e do simbólico para captar algo da insegurança das pessoas e o forte discurso de extrema-direita (como a imprensa internacional vem agora se referindo ao governo brasileiro) que se concretizou no Brasil: um discurso da ordem para um Eu pós-moderno inseguro, frágil diante do Supereu do goze, faça o que for melhor, sinta prazer. Não iremos discutir isso aqui, mas essa interpretação da fragilidade do eu é importante dentro desse quadro.
}

Nixon $^{8}$ a frear a convertibilidade, choques do petróleo e os petrodólares surgindo, os segmentos fortes da elite financeira, vendo seus lucros aumentarem cada vez mais em ativos financeiros e não em produção, ${ }^{9}$ trazem como

8 O período de governo do presidente Richard Nixon se estende de 1969 até 1974 renunciando depois. O interessante para nós neste ponto são algumas tensões geopolíticas durante o seu governo, dando novas configurações à economia e à geopolítica mundial, como o primeiro choque do petróleo, bem como, o rompimento da paridade ouro-dólar estabelecida em Bretton Woods, tornando assim o valor das moedas totalmente dependentes de um mercado altamente especulativo e volátil, ou seja, o mercado cambial. Isso permitiu às grandes corporações e à banca das finanças acumular desde então poder e riqueza como nunca visto.

9 Há muita coisa sobre isso na cultura popular a anunciar os novos tempos da pós-modernidade. Por partes: falar em pós-modernidade é muito amplo, e todo conceito amplo demais se perde em imprecisão e parece intelectualmente tóxico. Falar da pósmodernidade em filosofia não é a mesma coisa que em literatura etc. E esta nota está longe de anunciar essas marcas, diferenças ou definir pós-modernidade. Apenas mostrar que seus anúncios na cultura popular se faziam por algumas características, assim como há características em outros segmentos (como se disse na literatura, filosofia, artes etc.). Exemplos de seu anúncio na cultura popular são os yuppies - os jovens executivos, bem remunerados, gastando sua renda em artigos de luxo e atividades caras, modos de vida e hábitos altamente sofisticados e perdulários, provindo o termo yuppie da sigla "YUP", expressão inglesa para "Young Urban Professional" - e um dos seus melhores retratos em filmes é o de Oliver Stone em "Wall Street" (Wall Street, 1987) e o personagem simbólico do yuppie de Charlie Sheen, Bud Fox. É o "cara" que ganha quantias insanas de dinheiro apenas especulando. Mais ainda, seu mentor, interpretado por Michael Douglas, o grande abutre financeiro Gordon Gekko. Infelizmente, esses abutres estavam apenas engatinhando: o pior - percebemos hoje - estaria para vir. Para finalizar esta nota, o tema básico do filme é este: a produção contra a especulação, ninguém mais produz nada. Triste é que esse mantra permanece até hoje e pode ser visto por todo lado ainda, em filmes como Margin Call (2011), ou documentários como "Quants, os alquimistas de Wall Street" (Quants: The Alchemists of Wall Street, 2010). Interessante também neste contexto o filme "Fábrica de Loucuras" (Gung Ho, 1986) com Michael Keaton. Além de mostrar o que não se realizou, ou seja, a "dominação" japonesa - os chineses tomaram a dianteira - o filme mostra o panorama da competitividade e da produtividade que irão nortear nossas vidas até hoje. O título em inglês é mais adequado e mais honesto ideologicamente: é uma expressão chinesa para "trabalhe em conjunto". Em outros termos, somos livres para o capital e está bom demais. 
consequência uma imperiosa necessidade de reformular os processos produtivos. Dentro das grandes corporações multinacionais se destacam cada vez mais os departamentos financeiros. A solução está dada: desregulamentação de mercados, migração de capitais, terceirização de trabalhadores e de processos produtivos, Toyotismo e a flexibilização da produção ou acumulação flexível (HARVEY, 2013). Nada que não nos seja familiar: é a operação conhecida como "Consenso de Washington" e o neoliberalismo como solução para todos os problemas. Só não se disse os problemas de quem: os problemas de como fazer o capital aumentar sua acumulação.

Dentro desse quadro, o mundo do trabaIho aparece como? Com os fortes movimentos de desregulamentação de agentes financeiros, de conversão cada vez maior do capital para ativos e financeirização, as TICs fornecendo a base tecnológica não só para fluir o capital especulativo, mas ainda gerenciar em grande escala a desterritorialização do capital produtivo, bem como, flexibilizar e automatizar ao máximo a produção - a microeletrônica e a robótica estão integradas nesse processo - resta ao mundo do trabalho o que lhe era inevitável: a destruição de sindicatos, trabalho precário, terceirização, enfim todo e qualquer processo e projeto político-econômico de derrotar as forças do trabalho, suas facções de classe e a sua luta. A liberdade como horizonte político e dos desejos parece ficar cada vez mais distante. O mundo do trabalho dentro desse panorama parece ficar não apenas transformado, mas cada vez mais destruído.

Importante dentro desse panorama caótico a pergunta já posta como título, porém em outra chave discursiva. Ao invés de colocar se ainda é possível, talvez fosse mais adequado perguntar onde se coloca a educação profissional. A intenção de qualquer ensaio teórico, de qualquer tentativa de trazer a realidade para as lentes da teoria, para o âmbito restrito da espessura de um texto (este que agora fala ao leitor: nunca é a realidade, é sempre uma mediação teórica e muitas vezes ao esquecer isso "caímos em pecado" ao atribuir à realidade algo que não está e nunca esteve nela) deveria ser problematizar e colocar em xeque muitas de nossas concepções, ideias e conceitos. Justamente isso é o que faremos na última parte com o conceito de educação profissional e sua possibilidade.

\section{EdUCAÇÃO PROFISSIONAL: QUEM QUER SER NINGUÉM?}

O mundo do trabalho não está apenas cada vez mais destruído e subsumido ao capital em quase sua totalidade: agoniza melancólico. Sim, é pelo viés também da psicanálise que devemos enxergá-lo. Precisamos entender os movimentos do capital e o seu processo de produção de valor, reprodução da riqueza, concentração cada vez maior da mesma enquanto se destroem os trabaIhadores. A esse quadro das objetividades econômicas e tecnológicas, estratégicas e táticas, pois são políticas com claros objetivos de destruir o trabalho - o sonho do capital, se ele fosse uma pessoa e não uma relação social, seria um mundo automático de produção de riqueza, limpo (clean), sem pobres, todos felizes como só uma máquina pode ser - devemos acrescentar o corpo dos afetos daquele que agoniza e se vê desamparado: a massa dos deserdados como trabalhadores que só podem viver de si, de sua venda. Assim, a carne mais barata do mercado não é só mais a carne negra: todas as carnes são baratas se forem carnes humanas de trabalhadores. ${ }^{10}$

Não se tomará uma espécie estranha de ao "pé da letra histórico", ou seja, a educação profissional e sua história. É comum encontrarmos narrativas assim para explicar um conceito. Semelhante ao tentar elucidar um conceito pela sua etimologia que acaba perdendo o agora-já de sua significância, esse histórico parece com os esforços de fazer uma

10 Evidente que falamos da carne como corpo e nos demos o direito a metáforas. Os salários de negros e mulheres, por exemplo, sabemos bem e por estatísticas, continuam sendo mais baixos do que seus equivalentes brancos de "boa aparência" e mulheres. 
filogenia se transformar em uma ontogenia. ${ }^{11}$ Toda forma de trabalho precisa de uma educação e disciplinamento: faz parte da narrativa por nós já traçada neste ensaio; não é possível o trabalho sem disciplinamento das técnicas. Toda educação é formalização e uma condução de um eu que só se faz no outro. Estamos sempre e inevitavelmente na sociedade e suas formas de controle e disciplinamento. Nem na morte saímos dela: um corpo biológico desaparece como podridão e extinção até os ossos, porém o "eu" continua na mesma como a lembrança dos outros sobre nós. Por isso, a morte nunca é nossa: a morte é um ato social. Podemos colocar sempre o campo político de determinações da aposta: qual educação e qual educação profissional?

Com a urbanização promovida pela revolução industrial inglesa e a necessidade de disciplinamento de trabalhadores, passou a ser necessário o disciplinamento desde o sinal da escola. As primeiras gerações de trabalhadores fabris vinham do campo e não sabiam, não entendiam nada do tempo do trabalho: os tempos do trabalho do campo não são os mesmos da cidade e da indústria. Além de serem obrigados a aprenderem novas noções de tempo, de ritmo produtivo etc., seriam obrigados também a transformar seu universo perceptivo. A consciência nunca mais seria a mesma, pois nunca mais seriam os mesmos os sentidos. Os filhos desses primeiros trabalhadores seriam educados para entender o significado de tempo, de habilidades, competências, entre outros atributos para ser um bom trabalhador. Com a maquinaria e o setor metalúrgico, depois os desdobramentos mais e mais complexos dos sistemas produtivos e da administração ${ }^{12}$ ao longo do século XX, no-

11 Bastante semelhante é o que faz Lukács com o trabalho: ao transformá-lo em categoria para além da história e base de toda a sociabilização humana, faz uma filogenia ser o constituinte de uma ontogenia. Se, nesse ponto, colocar em xeque, "estocar" esses conceitos, é ser "pós-moderno", preferimos esse rótulo a uma narrativa nada afeita a ser mais cuidadosa com as complexidades sociais e novas epistemes.

12 Uma coisa era administrar uma pequena fábrica do final do século XVIII e início do XIX. Bem diferente é com a emergência da grande indústria, o capital vas profissões e campos de conhecimento vão se delineando. Para ser um profissional neste momento, são necessárias instruções cada vez mais específicas. Respondemos, assim, o que atrás formulamos como contraponto da pergunta a intitular este ensaio: onde se coloca a educação profissional? Coloca-se neste quadro de "fenomenologia do capital", 13 seus desdobramentos produtivos e necessidades profissionais mais específicas.

Entretanto, diante das transformações do mundo do trabalho assinaladas a partir dos anos 1970/1980 e a precarização cada vez maior do trabalho, dos terceirizados, do trabalho descartável, dos novos e crescentes disciplinamentos, da destruição crescente de postos de trabalho e sindicatos, da absurda inutilidade quase total do ser humano aparece o título deste ensaio: em que lugar podemos colocar a educação profissional e se ela é possível. Mais: deixamos de ter profissionais, temos "catadores de emprego". Observemos com calma este ponto e depois poderemos chegar à conclusão.

O universo ideológico e simbólico é fantástico. A ideologia interpela o indivíduo como sujeito, adverte-nos Althusser. Isso sig-

financeiro e o imperialismo: neste momento surgem as figuras dos acionistas industriais - o sistema por ações ou cotas não é novo, mas com o capitalismo do século XIX e início do XX ganha nova dimensão -, dos administradores para cuidarem dos negócios, a administração científica. Enfim, novos campos de trabalho, novas necessidades de conhecimento e instrução para o mesmo.

13 A forma pela qual a dinâmica do capital se impõe sobre nós em um aparecer que não é o capital (o capital é relação social e não realidade empírica, bruta, tanto que ele é um "coringa”, está sempre metamorfoseado em alguma forma), mas suas manifestações simbólicas e ideológicas. Por isso, o uso da "fenomenologia do capital” em uma espécie de paródia à Fenomenologia do Espírito de Hegel. Ver Žižek (1996) sobre o papel essencial da ideologia, bem como, Wilhelm Reich (1974) especialmente o capítulo primeiro no qual trilha por caminho semelhante ao de Žižek, apontando para a ideologia (e para nós as configurações simbólicas da intersubjetividade que ela produz) como poder de elevada autonomia. No entanto, não tínhamos e não há lugar para desenvolver neste texto a questão da ideologia e do poder simbólico como formas da configuração do próprio estado social e não apenas uma superestrutura. 
nifica que os poderes sociais buscam dentro do indivíduo seu sujeito e esse é um sujeito social do inconsciente. Ninguém quer ser ninguém: o reconhecimento social é parte de nós não objetivamente, não pelas mãos de uma consciência que se pensa e se diz: "quero ser reconhecido". Esse afloramento consciente até surge, mas provém das instâncias do Supereu freudiano. ${ }^{14}$ É neste momento que a ideologia como poder simbólico mediando as intersubjetividades captura o Es, o Isso freudiano, e não queremos ser ninguém, queremos reconhecimento e parte do mesmo se dá pela profissionalização. Bastante curiosos são os telejornais em suas entrevistas com "populares": sempre aparece o nome da pessoa entrevistada e sua profissão. Sem a profissão, de acordo com essa narrativa não somos nada. Por que não podemos apenas ser um ser humano? Uma curiosa história ilustra um pouco isso: conta-se que Einstein (pouco importa se isso está no universo dos mitos biográficos ou não, a narrativa está dada e, neste caso, acompanhamos Lacan: a realidade tem estrutura de ficção, a realidade é sempre um recorte e feito por alguém e de alguma forma) ao chegar aos EUA como imigrante teria preenchido os papéis da imigração e ao se deparar com a pergunta "raça" teria escrito, "humana”.

No entanto, a realidade atual é bem outra. A imensa maioria dos trabalhadores é de pessoas incluídas na sociedade mundial capitalista como "catadores de emprego". ${ }^{15}$ Podem ser formados, ter nível acadêmico, curso

14 Não cabe aqui explicitar o conceito bastante complexo de Supereu e com frequência mal explicado mesmo que em linhas gerais como nos adverte Marta Gerez-Ambertín (2003). Apenas assinalaremos sua complexidade como instância social atravessando o inconsciente em sua forma mais "bruta" de paixões no Es também freudiano. Por isso, o inconsciente não é individual como quer a crítica marxista vulgar, bem como, a leitura bastante vulgar da psicanálise como ego psychology.

15 Dizemos "incluídas" como aquelas que participam em algum nível da miséria humana vigente chamada capitalismo. Não consideramos aqui alguns bilhões que passam fome à margem de qualquer forma de emprego, não possuem o mínimo padrão ocidental de consumo de energia, entre tantos outros critérios. profissionalizante ou tecnológico: "pegam" o que aparece. Há algum tempo vimos chamando essas pessoas de os "não profissionais". E o quanto lhes dói na alma e no orgulho não serem reconhecidos. Esse trabalhador, portador de trabalho, logo essa força de trabalho profissionalizada, mas em qualquer lugar do espectro social que não o da sua profissão, não aquela na qual se formou, é um "não profissional” a agonizar melancólico. Ganha apenas o suficiente para tomar sua dose semanal de estímulo em uma cerveja - se sua renda-salário Ihe for suficiente. Se ganhar um pouco mais como gerente de recursos humanos de uma empresa, mas querendo concluir seu mestrado e ser professor de filosofia, talvez consiga uma renda-salário para o seu antidepressivo. ${ }^{16}$

Dentro dessas perspectivas que tendem a ampliar a tragicidade da vida, bem como, os horizontes do desamparo, do desemprego, da insegurança, da indefinição do que se é, obrigar-se a "ser alguém na vida" pela profissão - quando a expressiva maioria dos trabaIhadores está pensando em ganhar dinheiro onde ele estiver, "catando emprego" - qual lugar se pode dar para a educação profissional? A resposta é passível de multiplicidades de aspectos e encaramos aqui apenas dupla possibilidade entremeada pelo já exposto.

Por sua vez, uma educação profissional para a liberdade. Algo bastante parecido com o destaque já oferecido por nós em outra oportunidade (DOTI, 2018a). Liberdade, nesse caso, se refere a uma crítica radical das formas atuais de formação profissional e de educação para o útil: a finalidade da educação não é essa. A educação é fazer o sofrimento da perda de si inevitável em sociedade transformar-se em sociabilidade, em base de uma vida de experiências múltiplas e uma profissão como parte desse todo. A formação como educação, uma construção humana para a diversidade é a base de

16 Quem sabe o tom dramático dessa realidade nos permita lembrar algo um tanto triste e dramático também: os versos iniciais de "Nowhere Man" dos Beatles:

He's a real nowhere man

Sitting in his nowhere land

Making all his nowhere plans for nobody. 
uma educação profissional em qualquer campo. Não vamos nos furtar neste final ao que fizemos durante todo este ensaio, ou seja, usar e ousar com ideias beirando ao poético ou metafórico: educar para formar o humano é já a profissão de "ser humano".

O outro lado a ser visto dentro da dupla possibilidade apontada é o que nos oferecem como EPT ou educação profissional instituições como Sesi, Senai, Ceeteps etc. Trata-se de uma limitação dos potenciais humanos. O discurso dessas instituições configura uma narrativa não profissionalizante, mas "tecnicista”. Por isso, não estranha uma concepção a permear a atualidade dessas instituições: a educação profissional embrenhada em forças simbólicas e sobre determinada configuração de trabalho e sentido da existência do que formação humana e cidadã. ${ }^{17}$ Temos um campo ideológico a gerir um simbólico que diz mais ou menos assim à subjetividade: "aqui está sua profissão, aqui oferecemos as técnicas e os instrumentos para você ser alguém, se não conseguir é fracasso seu". Precisa mais para destruir um ser humano? Diante disso, preferimos a nossa opção: a educação para o desejo de "ser humano" é muito mais do que alguém. Ao tornar-se em seu potencial de não sofrimento, podemos ser alguém e não a sombra do desejo de outro. Não queremos e nem buscamos a "ninguendade", buscamos um desejo de reconhecimento social e individual: ser um é ser o outro, pois, afinal, o "eu sou um outro".

\section{REFERÊNCIAS}

CUPANI, Alberto. Filosofia da tecnologia: um convite, 3. ed. Florianópolis: Editora da UFSC, 2016.

BOLTANSKI, Luc; CHIAPELLO, Ève. O novo espírito do capitalismo. São Paulo: Martins Fontes, 2009.

DARDOT, Pierre; LAVAL, Christian. A nova razão do mundo: ensaio sobre a ordem neoliberal. São Paulo: Boitempo, 2016.

DELEUZE, Gilles; GUATTARI, Félix. O que é a filosofia. São Paulo: Editora 34, 2010.

DOTI, M. M. Sociedade, natureza e energia: condições estruturais e superestruturais de produção no capitalismo tardio. São Paulo: Editora Edgard Blucher, 2008.

17 Há questão aqui a ser mais bem tratada do ponto de vista específico. Qual seja: o estudo das escolas e faculdades de formação tecnológicas como aqui referidas e seu panorama no contexto da educação profissional, tecnológica e, "subindo mais ao conceito", ou seja, a um universal concreto, dentro da função da educação dentro da narrativa posta neste artigo. Dessa maneira, exigiria outro estudo uma vez que há práticas docentes emancipatórias e críticas dentro das referidas instituições e aqui fizemos "tábula rasa", pois o espaço e o ponto de vista o exigiam. Salienta-se, porém, que é inevitável pensarmos nos múltiplos aparelhamentos destas instituições. Assim, temos aparelhamento político delas, discursos homogêneos muitas vezes da grade curricular na forma de geração de renda e empregabilidade etc. Nosso ponto de vista foi de crítica radical a essa formação. Devido a experiências específicas dentro de algumas das instituições do Sistema S, podemos ver que os ideais de formação do cidadão como todo com o trabalhador perderam-se nas figuras dos próprios diretores transformados em gestores (MÜLLER, 2010). Não nos alongaremos além disso, mas esse discurso e a construção da narrativa profissional dentro de tais instituições podem ser auferidos pela conta dos discursos dos gestores e como isso vêm liquidando a teoria social e a colocando dentro das instituições profissionais como um "novo espírito do capitalismo" (BOLTANSKI; CHIAPELLO, 2009) assim como, produzindo uma "nova razão do mundo", por meio da "governamentalidade" (FOUCAULT) na conquista da linguagem e, portanto, do próprio ato de desejar (DARDOT; LAVAL, 2016). 
. "Crise energética: manifestação da crise do capital”. In: MAZIN, A. D. et al. (Orgs.). Questão agrária, cooperação e agroecologia. São Paulo: Outras Expressões, 2016a, p. 233-254.

. As tecnologias e o desenvolvimento: conceitos para pensar a formação em EPT. In: XI WORKSHOP DE PÓS-GRADUAÇÃO E PESQUISA DO CENTRO PAULA SOUZA, Centro de Pós-Graduação do CPS, São Paulo, 2016b.

. "Subjetividade e Revolução: para a crítica radical da contemporaneidade do capital absoluto". In: LIMA FILHO, P. A. et al. (Orgs.). Movimentos sociais e crises contemporâneas à luz dos clássicos do materialismo crítico. Uberlândia: Navegando Publicações, 2017a, p. 225-246.

. "Inovação ou democracia: aporia das instituições". In: XII WORKSHOP DE PÓS-GRADUAÇÃO E PESQUISA DO CENTRO PAULA SOUZA. São Paulo, 3 a 5 de outubro de $2017 \mathrm{~b}$, ISSN: 2175-1897.

. "Onde começa a EPT”. In: FREIRE, E.; VERONA, J. A.; BATISTA, S. S. S. Formação Tecnológica: extensão e cultura. Jundiaí: Editora Paco, 2018a.

. Tecnologias como linguagem: configurações atuais da sujeição e dominação. In: II SIMPÓSIO NACIONAL EDUCAÇÃO, MARXISMO, SOCIALISMO, n. II, 2018b, Belo Horizonte, UFMG. Disponível em < https://www.simposioedumarx.com.br/trabalhos-completos-mesas-de-discus> Acesso em: 23 de outubro de 2018b.

. Transformações Digitais: Potencialidade e Sujeição. In: XIII WORKSHOP DE PÓS-GRADUAÇÃO E PESQUISA DO CENTRO PAULA SOUZA. São Paulo, 16 a 19 de outubro de 2018c, ISSN: $2175-1897$.

. A sujeição atual: a captura dos afetos pela super-realidade. In: XI CONGRESSO INTERNACIONAL DE TEORIA CRÍTICA. Araraquara, Unesp/FCL, dias 1 a 5 de outubro de 2018d (prelo).

. "Técnica como linguagem e escrita do mundo". In: Revista Eletrônica de Tecnologia e

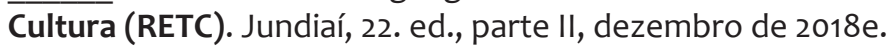

DUCASSÉ, Pierre. História das técnicas. Lisboa: Publicações Europa-América, 1962.

DUNKER, Christian Ingo Lenz. Mal-estar, sofrimento e sintoma. São Paulo: Boitempo, 2015.

FREUD, Sigmund. Além do princípio do prazer. In: Obras Completas, v. 14. São Paulo: Companhia das Letras, 2010.

. Compêndio de psicanálise. Porto Alegre: L\&PM, 2014.

GAMA, Ruy. A tecnologia e o trabalho na história. São Paulo: Nobel/Edusp, 1986.

GARCIA-ROZA. Luiz Alfredo. Acaso e repetição: uma introdução à teoria das pulsões, 4. ed. Rio de Janeiro: Zahar Editores, 1986.

GEREZ-AMBERTíN, Marta. As vozes do supereu: na clínica psicanalítica e no mal-estar da civilização. São Paulo/Caxias do Sul (RS): Cultura Editores Associados/ EDUCS, 2003. 
GIACOIA, O. Além do princípio do prazer: um dualismo incontornável. Rio de Janeiro: Civilização Brasileira, 2008.

HARVEY, David. A condição pós-moderna. 24 ed. São Paulo: Loyola, 2013.

MARX, Karl. O capital: crítica da economia política. Livro I, O processo de produção do capital (Tomo 1). São Paulo: Nova Cultural, 1985.

MÜLLER, Meire Terezinha. “O Senai e a educação profissionalizante no Brasil”. In: Revista HISTEDBR On-line. Campinas, n. 40, p. 189-211, dez. 2010.

PINTO, Álvaro Vieira. O conceito de tecnologia. Rio de Janeiro: Contraponto, 2005.

POSTONE, Moishe. Tempo, trabalho e dominação social: uma reinterpretação da teoria crítica de Marx. São Paulo: Boitempo, 2014.

REICH, Wilhelm. Psicologia de massa do fascismo. Porto: Publicações Escorpião, 1974.

SCHÖPKE, Regina. Por uma filosofia da diferença: Gilles Deleuze, o pensador nômade. Rio de Janeiro: Contraponto Editora, 2012.

ŽIŽEK, Slavoj (Org.). Um mapa da ideologia. Rio de Janeiro: Contraponto Editora, 1996.

\section{MARCELO MICKE DOTI}

Graduado em Ciências Econômicas (Unesp/FCLAr), mestrado em Filosofia Política (Unicamp/ IFCH) e em Sociologia (Unesp/FCLAr), doutorado em Planejamento de Sistemas Energéticos (Unicamp/FEM) e pós-doutorado em Pesquisas Energéticas (UFABC/CECS). Professor e pesquisador do Centro Estadual de Educação Tecnológica Paula Souza (CEETEPS).

Submetido em: 24-11-2018

Aceito em: 10-10-2019 